\title{
Gerakan Bersih-Bersih Pantai Balekambang dari Sampah Plastik
}

\author{
Nazriati, Yudhi Utomo, Fauziatul Fajaroh, Suharti, Danar, Endang Ciptawati \\ Fakultas Matematika \& IImu Pengetahuan Alam, Universitas Negeri Malang \\ Jl. Semarang 5, Malang, 65145 Indonesia
}

ARTICLE INFO:

Received: 2019-06-21

Revised: 2020-10-11

Accepted: 2020-05-20

\section{Keywords:}

Balekambang beach, Environment, Plastic, Waste

\section{ABSTRACT}

The beach is an attractive place to unwind from your daily routine. The beauty of the beach must always be maintained so that comfort can still be obtained for everyone who visits it. The beach becomes a comfortable place if cleanliness is maintained. Plastic waste, if any along the coast, can be carried by the waves into the ocean. Plastic waste brought to sea can be consumed by marine biota because marine biota cannot distinguish between plastic and food waste. This community service activity intends to inspire visitors (tourists), managers and traders at Balekambang beach to care about the environment. A well-preserved environment will be a legacy that will be left on the next generation. The survey results show that visitors understand the meaning of waste and are willing to dispose of waste in its place.

(c) 2020 Published by University of Merdeka Malang. This is an open access article distributed under the CC BY-SA 4.0 license (https://creativecommons.org/licenses/by-sa/4.0/)

How to cite: Nazriati, Utomo Y., Fajaroh F., Suharti, Danar, Ciptawati E. (2020). Pelatihan Gerakan Bersih-Bersih Pantai Balekambang dari Sampah Plastik. Abdimas: Jurnal Pengabdian Masyarakat Universitas Merdeka Malang, 5(2), 139-144. https://doi.org/10.26905/abdimas.v5i2.3573

\section{PENDAHULUAN}

Bumi kita terdiri atas daratan dan perairan. Begitu juga Indonesia, wilayahnya meliputi daratan dan perairan. Wilayah daratan Indonesia $1.919 .440 \mathrm{~km}^{2}$ dan lautan $3.273 .810 \mathrm{~km}^{2}$. Luasnya lautan memberi kehidupan bagi rakyat Indonesia karena banyaknya sumber daya alam yang terkandung di dalamnya. Akan tetapi bila kehidupan di lautan tidak dijaga maka akan memberi dampak tidak baik bagi sumber daya alam yang terdapat di dalamnya dan berimbas juga bagi manusia.

Malang Raya sebagai bagian wilayah Indonesia memiliki banyak pantai yang dikomersialkan sebagai tempat wisata. Wisata pantai menjadi tujuan masyarakat untuk melepaskan penat, refreshing dari kejenuhan pekerjaan, gathering kantor, kegiatan keluarga, dan lainnya. Namun, komersialisasi pantai tersebut dapat menimbulkan dampak bagi keberadaan pantai tersebut dan juga kehidupan makhluk di laut. Salah satu 
ABDIMAS: Jurnal Pengabdian Masyarakat Universitas Merdeka Malang

Volume 5, No 2, Juli 2020: 139-144

pantai di Malang yang telah dibuka tahun 1978 yaitu Pantai Balekambang. Pantai Balekambang terletak di Kecamatan Bantur, Malang dan berada sejauh 60 kilometer ke arah selatan.

Pengelolaan pantai Balekambang sebagai salah satu destinasi wisata harus mematuhi aturan dan undang-undang yang berlaku. Undang-undang no. 10 Tahun 2009 tentang kepariwisataan pada pasal 5 butir (d) menyatakan bahwa kepariwisataan dengan prinsip memelihara kelestarian alam dan lingkungan hidup. Dan pasal 24 menyatakan bahwa setiap orang berkewajiban (1) menjaga dan melestarikan daya tarik wisata; dan (2) membantu terciptanya suasana aman, tertib, bersih, berperilaku santun, dan menjaga kelestarian lingkungan destinasi pariwisata.

Banyaknya pengunjung dan beragam usia dan budaya ke wilayah pantai Balekambang dapat meningkatkan perekonomian masyarakat sekitar karena dapat menghidupkan kegiatan ekonomi masyarakat. Namun, banyaknya pengunjung juga dapat menimbulkan masalah lain. Pengunjung yang berwisata seharian penuh memerlukan kebutuhan untuk makan dan lainnya. Makanan dapat mereka bawa dari rumah dan juga dapat dibeli di penjual sekitar pantai Balekambang. Hal inilah yang menjadikan timbulnya masalah karena diperlukan kesadaran masyarakat untuk membuang sampah pada tempatnya (Mustain, 2019). Akan tetapi tidak semua orang memahami atau memiliki budaya hidup bersih. Pada hal dalam Undang-undang No. 10 di atas menyatakan bahwa setiap orang berkewajiban membantu terciptanya suasana aman, tertib, bersih, berperilaku santun, dan menjaga kelestarian lingkungan destinasi wisata.

Destinasi wisata yang bersih akan mengangkat citra dari tempat wisata itu sendiri dimana saat ini masyarakat memiliki ketergantungan yang sangat tinggi terhadap internet terutama media sosial. Media sosial adalah salah satu media komunikasi dan interaksi andalan bagi sebagian besar masyarakat untuk mendapatkan informasi apapun terutama terkait dengan segala bidang (Sonalitha, 2019). Kebersihan, kenyamanan, keamanan dan sehat merupakan suatu keadaan yang menjadi target bagi pemerintah dalam menjalankan pemerintahannya. Tujuan tersebut dapat terlaksana melalui beberapa tatanan dan kegiatan yang saling berhubungan dan disepakati bersama oleh masyarakat dengan pemerintah dalam rangka meraih lingkungan sehat (Sonalitha, 2019).

Hasil survei di lapangan menunjukkan tidak semua pengunjung memiliki kesadaran akan kebersihan. Pengunjung ada yang membuang sampah sembarangan misalnya di daerah pasir tempat mereka bermain, di bawah jembatan yang menghubungkan pantai dengan pulau Ismoyo. Perilaku pengunjung yang demikian dapat menyebabkan pada saat pasang maka sampah tersebut dapat terbawa ke lautan. Pencemaran di wilayah pantai bisa disebabkan adanya sampah organic dan non-organik. Menurut Darmawi (2017) bahwa komposisi volume sampah organik pada kawasan wisata pantai $63,26 \%$ merupakan daun-daun, 33,27\% sisa limbah rumah makan. Efek lanjutannya dapat menimbukan pencemaran di laut dan lebih bahaya lagi bila sampah yang terbawa adalah non-organik (sampah plastik) yang degradasinya ratusan tahun karena tidak mudah terurai (Megawan \& Suryawan, 2019). Banyaknya sampah non-organik juga ditemukan pada Pantai Amal Baru Tarakan Kalimantan Timur, dimana didapatkan hasil sampah terbanyak adalah sampah plastik, seperti bungkus makanan, botol plastik bekas, peralatan plastik, dan jenis sampah lain yang berbahan dasar plastik (Abrori \& Listiani, 2017). Plastik komersial yang sering digunakan diantaranya polietilen (PE), polipropilen (PP), Polivinilklorida (PVC), polistirena (PS), dan lain-lain. Masing-masing plastik tersebut memiliki densitas yang bervariasi. Dengan demikian, sampah platik dapat terdistribusi pada berbagai ke dalaman misalnya ada yang di permukaan, ada yang di ke dalam sedang, dan ada yang sampai di laut dalam (Gorokhova, 2015). PE memiliki densitas tinggi sehingga sampah PE dapat sampai ke laut dalam atau ke dasar laut. Di samping itu, sampah plastik kadangkala dianggap ubur-ubur oleh 
hewan laut yang mangsanya ubur-ubur tersebut sehingga dikonsumsi oleh hewan tersebut. Fakta ini telah terjadi di Indonesia, dimana telah ditemukan ikan paus mati dan ditemukan di dalam perutnya $5,9 \mathrm{~kg}$ sampah plastik (Wismabrata, 2018). Untuk itu, kesadaran setiap orang perlu ditingkatkan bila berwisata ke pantai agar tidak menjadi penyumbang dampak negatif terhadap lingkungan laut dan biota di dalamnya.

\section{METODE}

Kegiatan pengabdian dilakukan di pantai Balekambang, Malang pada bulan Oktober 2019. Sasarannya adalah pantai belekambang dengan berkoordinasi dengan pengelola yaitu PT. Yasa Jasa.

Metode pelaksanaan yaitu dengan terjun langsung kegiatan bersih-bersih pantai di sepanjang pantai Balekambang terutama terhadap sampah plastik. Dalam pelaksanaan kegiatan pengabdian ini dilakukan beberapa hal berikut: (1) Koordinasi awal dengan tim pengabdian. (2) Survei lokasi untuk melihat keadaan pantai Balekambang dan mengetahui hal yang perlu dipersiapkan dalam kegiatana bersih-bersih pantai. (3) Bersurat ke PT. Jasa Yasa untuk mendapatkan izin untuk melaksanakan kegiatan pengabdian. (4) Mempersiapkan peralatan yang diperlukan dalam kegiatan bersih-bersih pantai Balekambang. (5) Meminta surat pengantar ke PT. Jasa Yasa untuk pada tanggal pelaksanaan kegiatan pengabdian. (6) Koordinasi akhir dengan tim pengabdian sebelum pelaksanaan.

\section{HASIL DAN PEMBAHASAN}

Kegiatan pengabdian dengan judul "gerakan bersih-bersih pantai balekambang dari sampah plastik" diawali dengan audiensi ke PT. Jasa Yasa untuk minta izin, penentuan waktu pelaksanaan, dan teknis pelaksanaan program pengabdian ini yang dilaksanakan oleh dosen Jurusan Kimia FMIPA UM dan melibatkan mahasiswa S1 dan S2 Jurusan Kimia UM. Kegiatan dengan melibatkan mahasiswa juga telah dilakukan oleh Abrori \& Listiani (2017) di Pantai Amal Baru Tarakan, Kalimantan Timur. Pemberdayaan mahasiswa dalam pembersihan sampah di Pantai Amal Baru dilakukan melalui shore cleanup.

Survei lokasi dan kebutuhan di lokasi pengabdian dilakukan terlebih dahulu sebelum dilaksanakan kegiatan pengabdian.

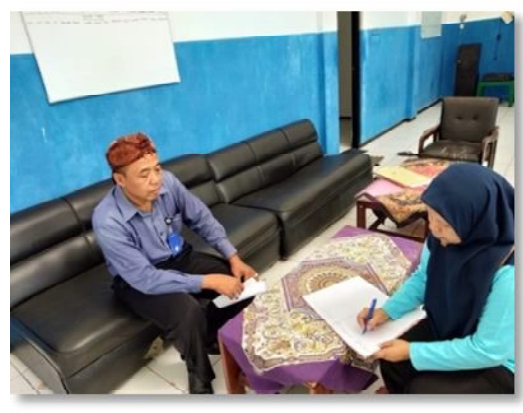

Gambar 1. Pengisian buku tamu

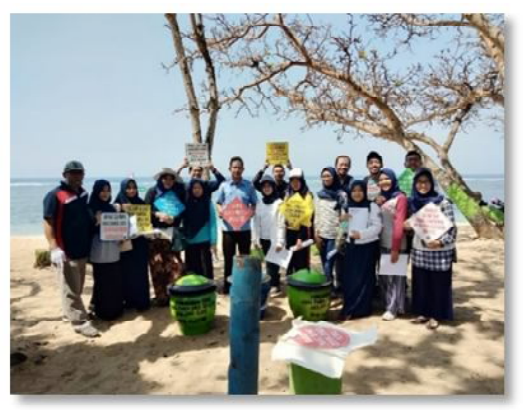

Gambar 2. Penyerahan tong sampah dan slogan secara simbolis ke pengelola pantai

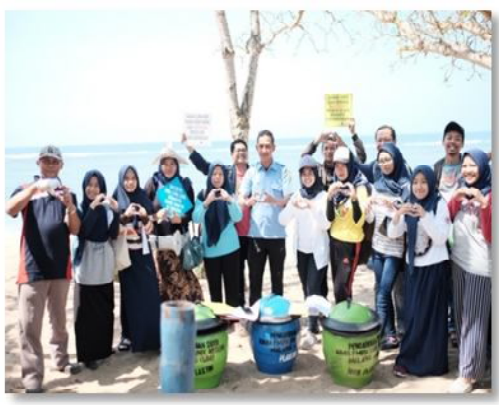

Gambar 3. Sebelum bersih-bersih pantai dengan tangan membentuk logo cinta terhadap lingkungan 
ABDIMAS: Jurnal Pengabdian Masyarakat Universitas Merdeka Malang

Volume 5, No 2, Juli 2020: 139-144

Kegiatan pengabdian dilakukan pada hari Sabtu tanggal 12 Oktober 2019. Tim pengabdian diterima oleh Kepala Seksi Pengelola Balekambang, Bapak Yasdi berserta staf. Sebelum turun ke pantai, kami berkoordinasi dan mengisi buku tamu (Gambar 1).

Pada pertemuan tersebut kami juga menyampaikan bahwa untuk mendukung kebersihan pantai balekambang kami menyerahkan tong sampah dan slogan himbauan agar wisatawan dapat menjaga kebersihan dan peduli terhadap lingkungan. Kedatangan kami bertepatan dengan akan diadakannya kegiatan lomba kebersihan yang akan diikuti oleh pantai Balekambang.

Pihak pengelola pantai menerima tong sampah dan slogan secara simbolis (Gambar 2) dan melakukan foto Bersama (Gambar3). Kami tidak melakukan penataan tong sampah dan pemasangan slogan di sepanjang pantai karena akan dilakukan langsung oleh pihak pengelola.

Selesai serah terima tim pengabdian Kimia UM segera melakukan kegiatan bersih-bersih pantai dengan mengambil sampah plastik yang ada di sepanjang pantai. Semua tim memakai sarung tangan dan membawa kantong untuk mengumpulkan setiap sampah yang ditemukan. Sampah tersebut dapat ditemukan sampai ke bibir pantai. Bila ditinjau dari jenis plastiknya maka sampah tersebut di antaranya berupa Polietilen (PE), polietilena tereftalat (PET), dan polipropilen (PP).

Sampah plastik yang sampai ke bibir pantai suatu saat dapat terbawa ke laut karena dibawa oleh ombak. Setiap jenis plastik tersebut mempunyai sifat tertentu seperti massa jenis. Hal ini menjadikan sampah plastik tersebut dapat tersebar di laut seperti di permukaan, di kedalaman tertentu, hingga sampai ke laut dalam (Cassola et al., 2019; Enggara, Bahrum, \& Suherman, 2019). Kondisi pantai yang banyak sampah plastik dapat dilihat pada Gambar 4 dan Gambar 5.

Sampah plastik dikumpulkan di sepanjang pantai Balekambang yang ramai dikunjungi pada hari Sabtu dan Minggu. Sampah plastik yang ditemukan berupa botol minuman, gelas minuman, sedotan plastik, pembungkus makanan ringan, pembungkus makanan seperti "cilok".

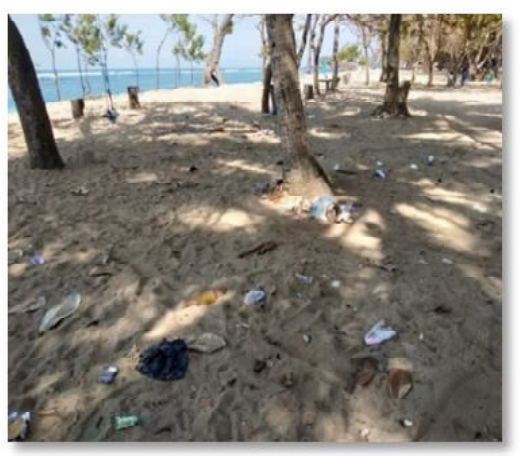

Gambar 4. Sampah plastik di pantai Balekambang

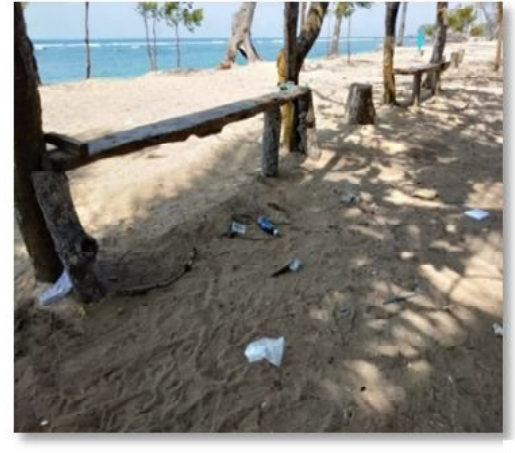

Gambar 5. Sampah plastik ditinggalkan di sembarang tempat

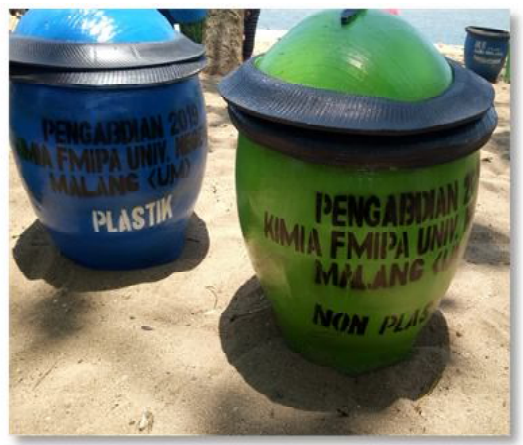

Gambar 6. Tong Sampah yang akan dipasang di sekitar Balekambang

Masuknya sampah plastik ke dalam lautan dapat menimbulkan berbagai efek. Sebelumnya telah diberitakan adanya ikan paus mati di Wakatobi dan ternyata di dalam perutnya terdapat 5,9 kg sampah plastik (Wismabrata, 2018). Satwa laut tidak dapat membedakan antara sampah plastik dengan makanan. Masuknya sampah plastik ke dalam pencernaan satwa laut dapat memblokir sistem pencernaan pada satwa tersebut dan dapat mengakibatkan kematian. Di samping itu, jenis sampah plastik lain dapat menyebabkan satwa laut terjerat/terperangkap ataupun tercekik. 
Sampah plastik yang terdapat di sekitar pantai Balekambang dapat disebabkan oleh: kurangnya tempat sampah yang tersedia di sepanjang pantai, kurang pedulinya masyarakat yang berkunjung ke pantai terhadap lingkungan, kurangnya slogan atau himbauan untuk peduli terhadap kebersihan pantai dan lingkungan, atau sebab lainnya. Pada kegiatan pengabdian ini, kami juga melakukan survei terhadap pengunjung tentang sampah. Pengunjung paham tentang sampah, mengetahui seharusnya sampah di buang kemana bila mereka menemukan sampah. Mereka juga bersedia menegur orang lain yang membuang sampah sembarangan. Pengunjung juga mau membayar lebih untuk masuk ke lokasi wisata pantai agar kebersihan lingkungan pantai dapat terjaga.

Tim pengabdian Jurusan Kimia dalam kegiatan ini membawa 20 tong sampah yang dapat dipasang di sepanjang pantai untuk mereduksi kekurangan tong sampah (Gambar 5). Tong sampah yang diberikan berasal dari ban bekas. Pemilihan jenis tong sampah ini karena di pantai udaranya mengandung garam yang dapat menyebabkan korosi bila tong sampah dari logam besi, bila dibuat dari bahan yang ringan dapat terbang karena angin di pantai kencang. Di samping itu, pembelian tong sampah dari bahan bekas ini dapat mengurangi limbah dan meningkatkan usaha kecil.

\section{SIMPULAN DAN SARAN}

\section{Simpulan}

Kegiatan pengabdian yang dilakukan mengajak pengunjung peduli terhadap lingkungan pantai. Pemasasangan slogan himbauan kepedulian terhadap lingkungan pantai akan menggelitik pengunjung untuk peduli akan lingkungan khususnya pantai. Penambahan tong sampah dapat memudahkan pengunjung menemukan tempat untuk membuang sampah sehingga sampah tidak dibuang di sembarang tempat. Semoga laut kita terjaga dari limbah plastik yang dapat merugikan biota laut dan akhirnya juga membahayakan manusia.

\section{Saran}

Perlu adanya sosialisasi, pendampingan dan monitoring dari pemerintah setempat secara berkesinambungan dan dapat dilanjutkan secara berkala untuk memelihara kebersihan dan keindahan panorama pantai Balekambang. Untuk pengabdi selanjutnya dapat melakukan pendampingan kepada masyarakat untuk dapat membuat tempat sampah sendiri (Setiyawan, 2016) serta juga untuk melakukan pendampingan agar masyarakat di sekitar dapat mengolah sampah plastik menjadi produk yang lebih bermanfaat (Ramadhan, Lelo, \& Rasyid, 2020). Dengan memanfaatkan sampah plastik tersebut diharapkan dapat meningkatkan penghasilan dan kesejahteraan mereka.

\section{DAFTAR PUSTAKA}

Abrori, F. M., \& Listiani. (2017) Pemberdayaan mahasiswa alam menjaga kebersihan Pantai Amal Baru melalui kegiatan pembersihan sampah. Jurnal Pengabdian Masyarakat Borneo, 1(1), 49-52. https://doi.org/10.35334/jpmb.v1i1.234

Cassola, G. E, Zadjelovic, V., Gibson, M. I., \& Oleza, J. A. C. (2019). Distribution of plastic polymer types in the marine environment: A meta-analysis. Journal of Hazardous Materials 369, 691-698. https://doi.org/10.1016/j.jhazmat.2019.02.067 
ABDIMAS: Jurnal Pengabdian Masyarakat Universitas Merdeka Malang

Volume 5, No 2, Juli 2020: 139-144

Chubarenko, I., Bagaev, A., Zobkov, M., and Esiukova, E. 2016. On some physical and dynamical properties of microplastic particles in marine environment. Marine Pollution Bulletin, 108(1-2), 105 112. https://doi.org/10.1016/j.marpolbul.2016.04.048

Darmawi, A. (2017). Potensi timbulan sampah pada objek pariwisata Pantai Baru di Kabupaten Bantul Yogyakarta. Jurnal Penelitian Teknologi Industri, 9(1), 61-71. https://doi.org/10.33749/jpti.v9i1.2907

Enggara, R., Bahrum, Z., \& Suherman, D. (2019). Kajian mekanisme penyebaran sampah di kawasan Pantai Pariwisata Kota Bengkulu sebagai penyebab degradasi nilai-nilai ekowisata. Naturalis: Jurnal Penelitian Pengelolaan Sumber Daya Alam dan Lingkungan, 8(2), 39-48.

https://doi.org/10.31186/naturalis.8.2.9208

Gorokhova, E. (2015). Screening for microplastic particles in plankton samples: How to integrate marine litter assessment into existing monitoring programs? Marine Pollution Bulletin, 99(1-2), 271-275. https://doi.org/10.1016/j.marpolbul.2015.07.056

Megawan, M. B., \& Suryawan, I. B. (2019). Pengelolaan sampah di daya tarik wisata Pantai Candikusuma, Desa Candikusuma, Kecamatan Melaya, Kabupaten Jembrana. Jurnal Destinasi Pariwisata, 7(2), 239-244. https://doi.org/10.24843/jdepar.2019.v07.i02.p05

Mustain, I. (2019). Aksi bersih sampah di Pantai Kejawanan Cirebon dalam membangun masyarakat sadar sampah. ABDIMAS: Jurnal Pengabdian Masyarakat, 2(2), 140-147. https://doi.org/10.35568/abdimas.v2i2.428

Ramadhan, A., Lelo, L., \& Rasyid, R. (2020). Pelatihan pemanfaatan sampah plastik sebagai material produk hiasan bagi lulusan SMA di Kota Tangerang. Abdimas: Jurnal Pengabdian Masyarakat Universitas Merdeka Malang, 5(1), 1-17. https://doi.org/10.26905/abdimas.v5i1.3083

Setiyawan, P. E. (2016). Penyuluhan tentang pengelolaan sampah dan pembuatan tempat sampah unik dari pipa PVC untuk masyarakat Desa Srigading Kecamatan Lawang. ABDIMAS: Jurnal Pengabdian Masyarakat Universitas Merdeka Malang, 1(1), 30-35. https://doi.org/10.26905/abdimas.v1i1.1172

Sonalitha, E., Yudhistiro, K., Soelaksono, A. G., Putri, D. M., \& Rofikhah, E. (2019). Kota sehat Kelurahan Gadingkasri Kota Malang. Jurnal Masyarakat Merdeka, 2(3), 8-13.

Wismabrata, M. H. (2018). 5 Fakta Kematian Paus di Wakatobi, 5,9 Kg Sampah Plastik di Perut hingga Ancaman Ekosistem Laut. https://regional.kompas.com/read/2018/11/ 22/15452011/5-faktakematian-paus-di-wakatobi-59-kg-sampah-plastik-di-perut-hingga?page=all. Diakses tanggal 12 Februari 2020. 